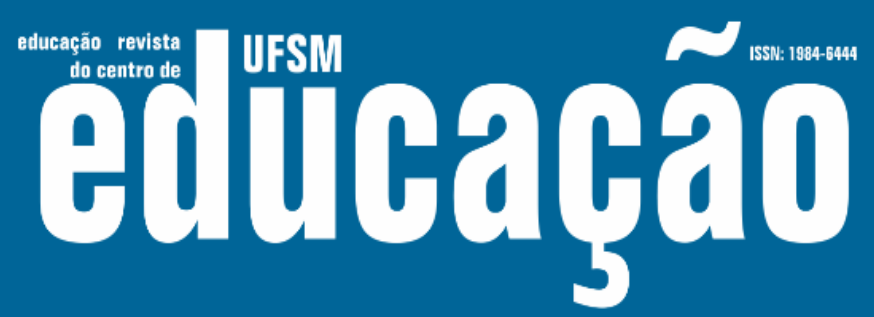

ISSN: 1984-6444 | http://dx.doi.org/10.5902/1984644436282

\title{
Consciência do direito: via de acesso à cidadania da pessoa com deficiência
}

\author{
Awareness of law: route of access to the citizenship of the person with \\ disability
}

Tatiana de Araujo Mendonça

Servidora pública federal trabalhando como assistente administrativo na Divisão de Acessibilidade e Inclusão da Universidade Federal Fluminense. Niterói, Rio de Janeiro, Brasil.

tatianamendonc04@gmail.com - http://orcid.org/0000-0002-8004-0875

Edicléa Mascarenhas Fernandes

Professora doutora na Universidade Federal Fluminense. Niterói, Rio de Janeiro, Brasil. professoraediclea.uerj@gmail.com - http://orcid.org/0000-0003-3998-2016

\section{Hélio Ferreira Orrico}

Professor doutor na Universidade Federal Fluminense. Niterói, Rio de Janeiro, Brasil. prof.helioorrico@gmail.com - http://orcid.org/0000-0001-7986-4407

Paulo Pires De Queiroz

Professor doutor na Universidade Federal Fluminense. Niterói, Rio de Janeiro, Brasil. ppqueiroz@yahoo.com.br - http://orcid.org/0000-0002-0609-6424

Recebido em 11 de janeiro de 2019

Aprovado em 15 de outubro de 2019

Publicado em 31 de janeiro de 2020

\section{RESUMO}

O presente trabalho trata da questão da inclusão da pessoa com deficiência - PcD no meio social. Utilizou-se de instrumento pedagógico voltado à remediação dos aspectos relativos à falta de conscientização e de conhecimento da própria $\operatorname{PcD}$ de seus direitos de cidadania plena protegidos por lei. Fundamenta-se na insuficiente motivação política dos tomadores de decisão em relação à problemática referida, no despreparo da comunidade em geral para influir objetivamente e relacionar-se de forma profícua e na frágil disposição da própria $\mathrm{PcD}$ para lutar pelos direitos que já lhe foram concedidos por lei. Para tanto, apoia-se em perspectiva pedagógica que se consubstancia em um programa de curso com foco na literatura de cunho histórico, filosófico e sociológico, como também no conhecimento da legislação pertinente, objetivando a melhor compreensão do quadro social da exclusão, pano de fundo desta realidade que busca remediar. $O$ curso é fruto de pesquisa cujo produto contribui para uma perspectiva de mudança nas atitudes e comportamentos que embasam o paradigma social da $\mathrm{PcD}$ na atualidade. O programa elaborado com base em um elenco de conteúdos constituído a partir da pesquisa desenvolvida foi aprovado por 


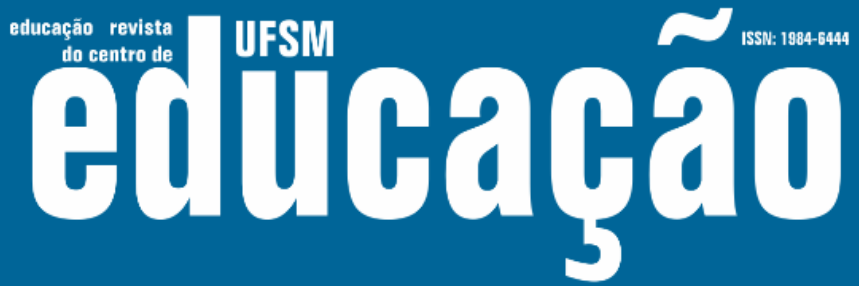

ISSN: 1984-6444 | http://dx.doi.org/10.5902/1984644436282

seus usuários após testagem, alcançando, ainda, repercussão dentro e fora do Brasil, o que permite concluir que seus objetivos foram encaminhados.

Palavras-chave: PcD; direito; cidadania.

\section{ABSTRACT}

This paper addresses the issue of the inclusion of person with disability in the social environment. It was managed through a pedagogical tool aimed to remediate the aspects related to the lack of awareness and knowledge of the own disabled person of their citizenship rights protected by law. It is based on the insufficient political motivation of decision makers regarding these issues, in the community general lack of prepare to directly influence and relate in a profitable way and in the fragile disposition of the own person with disability to fight for the rights already granted to them by law. For that, bases itself on a pedagogical bias to offer a course focused on the relevant historical, philosophical and sociological literature and also in the knowledge of the specific law aiming a better comprehension of the exclusion social framework of this reality that seeks to remediate. Specifically, the course arises from research whose outcome may contribute to a perspective of change in the attitudes and behaviors that support the person with disability's social model of nowadays. The program elaborated based in a set of contents obtained throught the research developed was approved by its users after testing, achieving, furthermore, impact inside Brazil and abroad, which allows to assume that its objectives have been directed.

Keywords: PwD; law; citizenship.

\section{Introdução}

O presente artigo fundamenta-se no cenário da vida social das PcD através dos tempos, para demonstrar a flagrante injustiça de que têm sido alvo em face do não reconhecimento de sua capacidade laborativa. Este fato ainda permanece na atualidade, a despeito de proeminentes figuras mundiais tais como Franklin Delano Roosevelt e o recentemente falecido Stephen Hawking. O primeiro, paralítico por poliomielite, foi eleito presidente dos Estados Unidos para quatro mandatos sucessivos e teve forte atuação para a solução dos conflitos da segunda grande guerra. O segundo, paciente de Esclerose Lateral Amiotrófica - ELA, destacou-se como brilhante cientista que deslumbrou o mundo. São eles exemplos, dentre muitos 


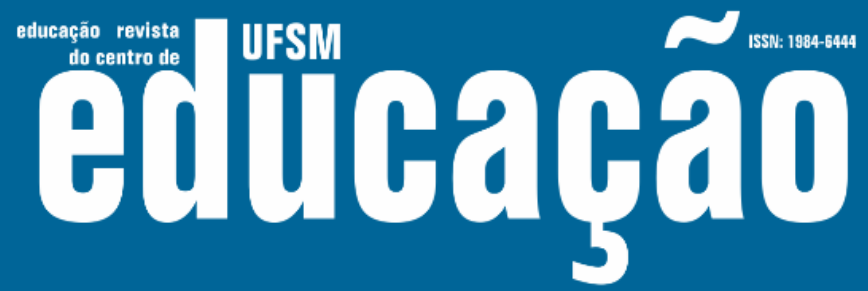

ISSN: 1984-6444 | http://dx.doi.org/10.5902/1984644436282

outros, a demonstrar que a limitação física e mesmo a intelectual não constituem barreira apta a toldar a grandeza do pensamento e do engenho humano.

No Brasil, Vinicius Garcia e Alexandre Maia, em artigo publicado no XVIII Encontro Nacional de Estudos Populacionais da Associação Brasileira de Estudos Populacionais- ABEP (2012. p.4) afirmam que a inclusão da PcD, historicamente, tem ocorrido por mérito individual, constituindo-se em um "processo errático e não-linear". A discriminação histórica possivelmente impregnou a memória social, a cultura e a conduta das pessoas, quer sejam $\mathrm{PcD}$, ou não.

A pesquisa: Expectativas e Percepções sobre a Inclusão de Pessoas com Deficiência no Mercado de Trabalho 2017-2018, realizada pelo I. Social com a Associação Brasileira de Recursos Humanos-ABRH e Catho embasa tais afirmações. Entrevistou-se 1.459 (hum mil, quatrocentos e cinquenta e nove) profissionais de RH baseando-se nos anos de 2014 a 2016. Segundo a pesquisa, as PcD correspondem a, aproximadamente, $23,9 \%$ (vinte e três vírgula nove) da população brasileira, ou seja, 1/4 (um quarto) dos seus habitantes. A inclusão social destas pessoas exige que se faça uma análise do problema sob os diversos aspectos que o compõem: Cultural, econômico, social e político.

Ousa-se afirmar que o fator cultural é determinador do quadro em descortino, servindo-lhe de pano de fundo. As consequências a que dá causa fundamentam-se, principalmente, no preconceito. A maioria dos profissionais entrevistados acreditam que as PcD sofrem preconceito por parte de gestores, colegas e clientes (Fig.1). 


\section{N

ISSN: 1984-6444 | http://dx.doi.org/10.5902/1984644436282

Figura 1: As Pessoas com Deficiência sofrem preconceito no ambiente de trabalho

\section{AS PESSOAS COM DEFICIÊNCIA SOFREM PRECONCEITO}

NO AMBIENTE DE TRABALHO
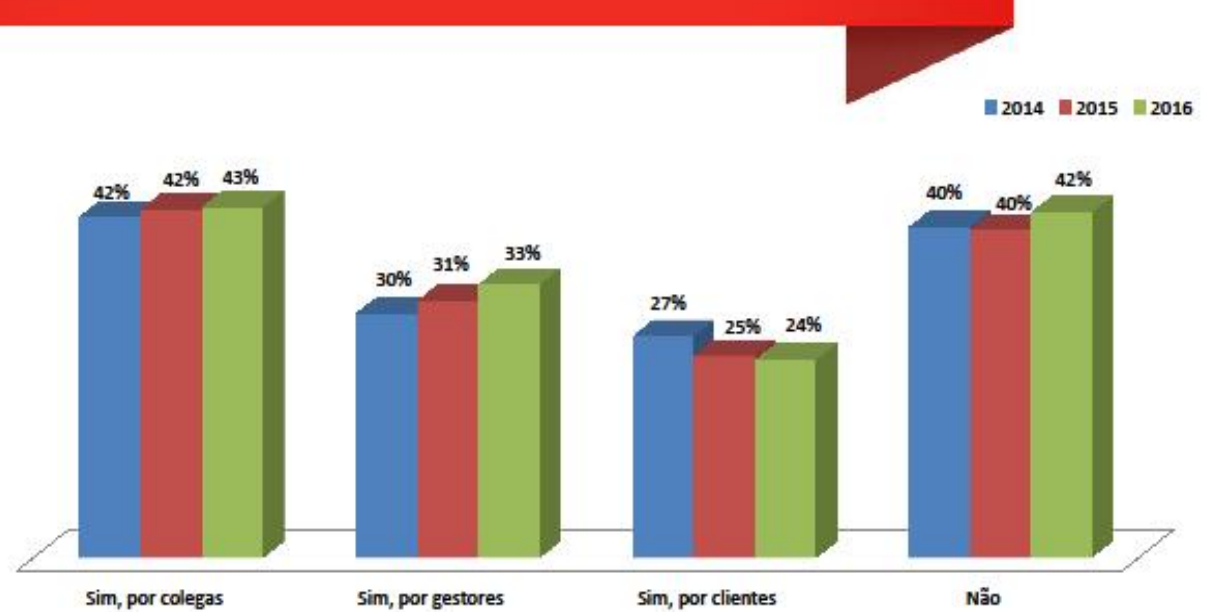

$70 \%$ dos entrevistados acreditam que as PcDs sofrem preconceito no ambiente de trabalho, seja ele por colegas, gestores ou clientes.

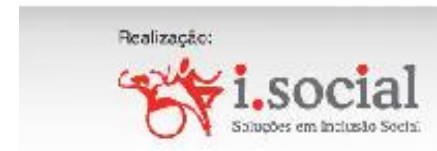

28
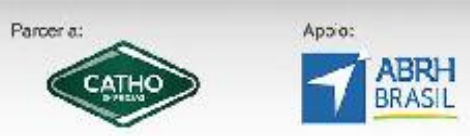

Fonte: http://isocial.com.br/isocialdownload.php

As dificuldades impostas às $\mathrm{PCD}$ as impossibilitam de prover sua própria subsistência e de contribuir para a dos demais a partir do momento que venham a integrar a força de trabalho do país. O fato é que a questão cultural é restritiva do progresso econômico-social e reclama medidas de caráter político-governamental. $\mathrm{O}$ percentual de $86 \%$ (oitenta e seis por cento) dos respondentes da pesquisa declarou contratar PcD apenas para cumprir a lei de cotas. Este percentual em 2014 era de $81 \%$ (oitenta e um porcento). Aqueles respondentes que atenderam a outras motivações mais favoráveis à $\mathrm{PcD}$, se analisados em relação à sequência histórica, apresentaram curva descendente de 19\% (dezenove) para 14\% (quatorze), conforme Fig.2: 


\section{OF HEM Ellibaral}

ISSN: 1984-6444 | http://dx.doi.org/10.5902/1984644436282

Figura 2: Motivos para as empresas contratarem pessoas com deficiência

\section{MOTIVOS PARA AS EMPRESAS \\ CONTRATAREM PESSOAS COM DEFICIÊNCIA}

— $2014=2015=2016$
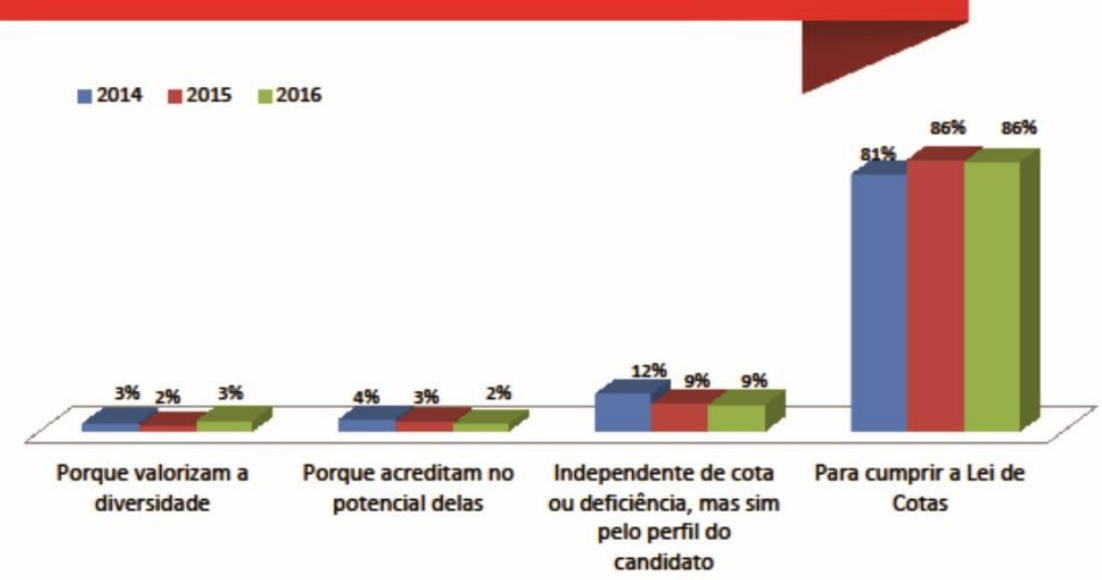

Preocupante. O cumprimento da legislação ainda é o principal motivo para as empresas contratarem pessoas com deficiência.
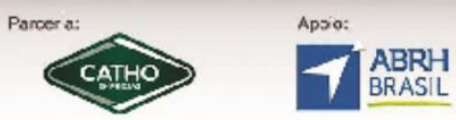

Fonte: http://isocial.com.br/isocialdownload.php

A pesquisa ainda nos oferece importante dado que pode contribuir para a reversão da baixa empregabilidade da $\mathrm{PcD}$ ao apontar a acessibilidade como principal barreira à sua empregabilidade (Fig.3). 


\section{Ej|lिa \\ 1SSN: $1984-6444$}

ISSN: 1984-6444 | http://dx.doi.org/10.5902/1984644436282

Figura 3: Principais barreiras para as Pessoas com Deficiência no mercado de trabalho

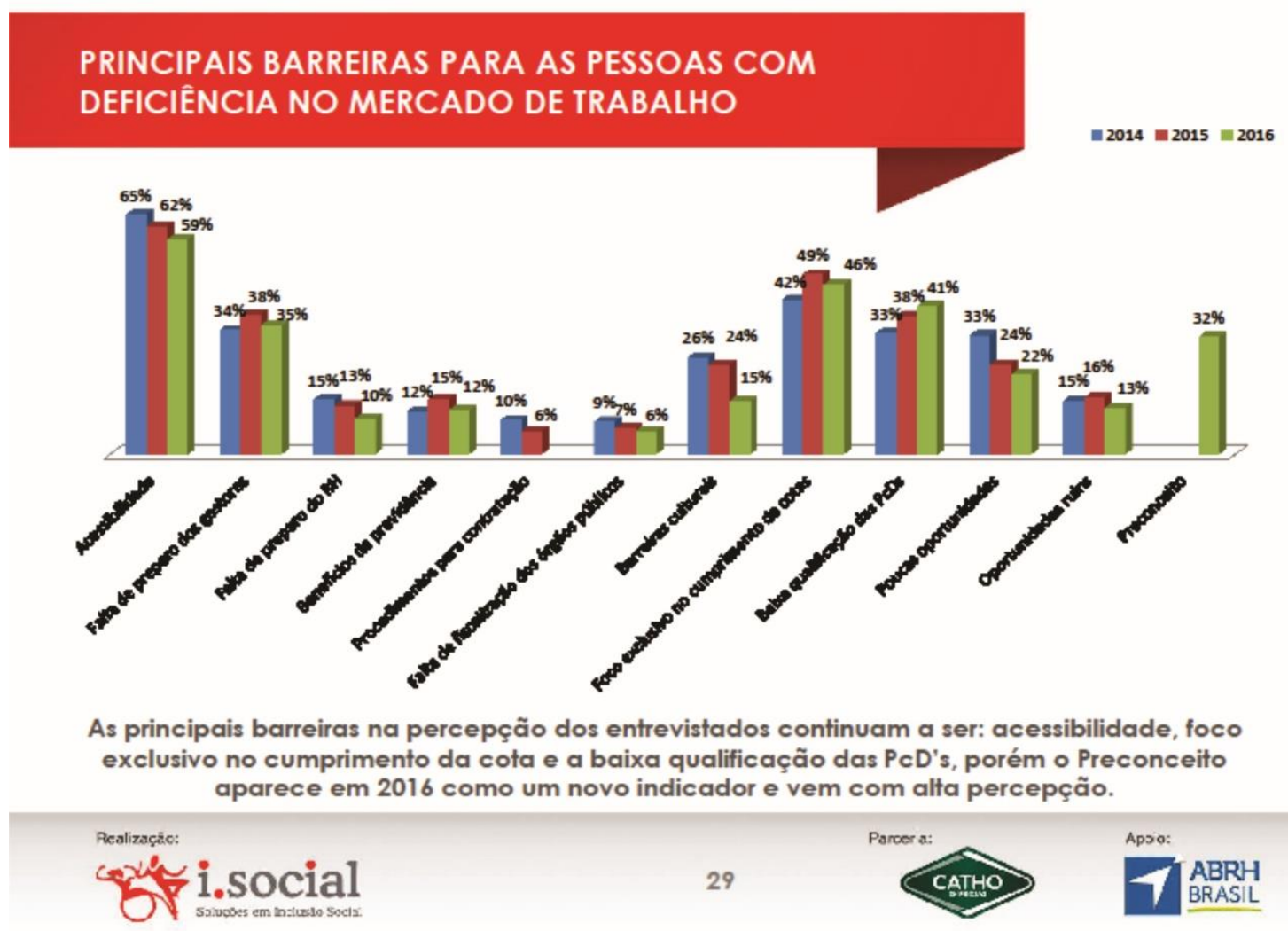

Fonte: http://isocial.com.br/isocialdownload.php

Ressalta-se que o tratamento da questão destacada já se encontra estabelecido por legislação específica, qual seja, a lei 10.098, de 19 de dezembro de 2000, mais conhecida como lei da acessibilidade. Este fato também representa importante encaminhamento econômico, social e político para a solução da questão da inclusão da PcD, considerando-se que o que se faz necessário para o afastamento da barreira se restringe ao cumprimento da lei, ou seja, ao cumprimento do que já está posto.

Prosseguindo no que se refere ao ponto de vista econômico, há que se atentar para o fato de que a inserção da PcD no mundo do trabalho teria impactos positivos na economia, tendo em vista que o quadro atual da previdência poderia ser invertido, passando elas de beneficiárias para contribuintes. Enquanto trabalhadoras, as PcD contribuiriam para a sociedade, deixando a condição de dependentes. 


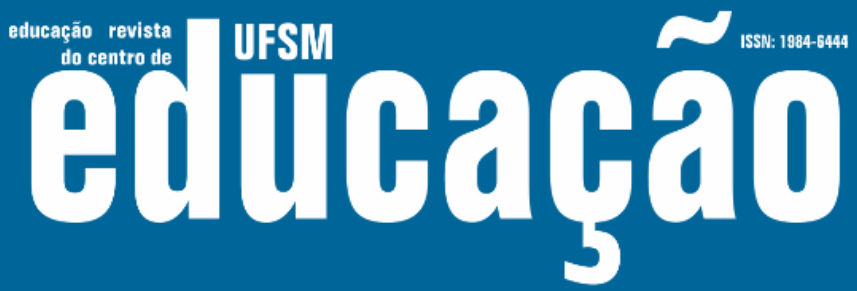

ISSN: 1984-6444 | http://dx.doi.org/10.5902/1984644436282

Sob o ponto de vista social, o sítio do Centro Regional de Informação das Nações Unidas-UNRIC declara que o grupo de PcD, em escala mundial, corresponde à maior minoria do mundo que, em dados numéricos, corresponde a 10\% (dez porcento) da população, ou seja, 650 (seiscentos e cinquenta) milhões de pessoas. Declara, ainda, que segundo o Programa das Nações Unidas para o Desenvolvimento-PNUD, "oitenta por cento do grupo supramencionado vive nos países em desenvolvimento", dentre os quais se inclui o Brasil.

Outros dados estatísticos de relevância ainda foram disponibilizados pelo referido sítio que dão conta de que o grupo de $\mathrm{PcD}$ corresponde a:

- $20 \%$ (vinte porcento) das pessoas mais pobres no mundo (Banco Mundial);

- $30 \%$ (trinta porcento) dos jovens que vivem na rua (Fundo das Nações Unidas para a Infância-UNICEF);

- $80 \%$ (oitenta porcento) das crianças com menos de 5 (cinco) anos que vêm a óbito em países onde este índice de mortalidade diminuiu para menos de $20 \%$ (vinte porcento);

- 386 (trezentos e oitenta e seis) milhões de pessoas em idade de trabalhar (Organização Internacional do Trabalho-OIT), sendo que, em alguns países, a taxa de desemprego atinge $80 \%$ (oitenta porcento).

Dados estatísticos do Censo de 2010, do Instituto Brasileiro de Geografia e Estatística- IBGE, disponibilizados no sítio Portal Brasil, dão conta de que 403,2 (quatrocentos e três vírgula dois) mil PcD atuam formalmente no mercado de trabalho, correspondendo a um percentual de $0,84 \%$ (zero vírgula oitenta e quatro porcento) do total dos vínculos empregatícios, segundo a Relação Anual de Informações SociaisRAIS, de 2015, divulgada pelo Ministério do Trabalho.

Para que esta realidade se modifique é preciso que se atente para o aspecto político da questão no que concerne ao investimento em políticas públicas. Estas carecem de serem efetivas e tendentes a privilegiar o desenvolvimento de ações destinadas à conscientização da sociedade em geral sobre a necessidade e a importância da inclusão destas pessoas em prol do bem comum, ou seja, de um contexto econômico-social solidamente pacificado. 


\section{Ism Autlathat

ISSN: 1984-6444 | http://dx.doi.org/10.5902/1984644436282

O cenário apresentado descortina, a partir dos dados levantados e respectivas inferências, embargos quantitativos e qualitativos para a inclusão das PcD que revelam um problema social com consequências para todos, quer sejam $\mathrm{PcD}$ ou não.

\section{Fundamentação teórica}

\section{0 fato e o direito. Entre o ser e o deve ser}

O Direito enquanto lei firmou-se como elemento extrínseco apenas com o decorrer do tempo, notadamente quando passou a constituir-se em instrumento de poder impessoal e objetivo exercido pelo governante (REALE, 2002, p. 145). Padrões foram constituídos e estabelecidos aos grupos sociais e passaram a ser impostos como norma, muito embora estas nem sempre tenham correspondido à vontade coletiva e ao interesse nacional (CASTRO, 1996, p.227).

Tomando por base os ensinamentos de Reale, pode-se dizer que o Direito visa atender "à exigência essencial e indeclinável de uma convivência ordenada, pois nenhuma sociedade poderia subsistir sem um mínimo de ordem, de direção e solidariedade" (REALE, 2002, p. 2).

Com fundamento na lógica de seus ensinamentos há que se aprofundar na compreensão do que seja o Direito e das bases que o fundamentam. Esta compreensão pode ser integral se tomada como base sua Teoria Tridimensional que defende a correlação entre as perspectivas de fato, valor e norma, vistas a partir de uma dinâmica de inter-relações voltada à constituição de uma unidade ou à concretude da experiência jurídica (REALE, 2002, p. 68). Estas bases constitutivas (REALE, 2002, p. 64-65), configuram-se conforme segue:

- O direito como fato, que diz respeito à sua efetividade social e histórica;

- O direito como valor, que confere dada significação a este fato;

- E, o Direito como norma, representativo do próprio Direito como ordenamento e sua respectiva ciência ou ainda como representativo da relação ou da medida que integra aqueles elementos, um ao outro, ou seja, que integra o fato ao valor. 


\section{Hism FutlaghaO}

ISSN: 1984-6444 | http://dx.doi.org/10.5902/1984644436282

É no próprio momento da consecução da estrutura normativa gerada pela correlação fato e valor que o Direito se realiza (REALE, 2002, p. 67). Fato, valor e norma, para a concretude da compreensão almejada precisam coexistir como unidade concreta e integrada de uma mesma experiência jurídica dialética do Direito e enquanto expressão de uma realidade histórico-cultural (REALE, 2002, p. 65).

Vem, ainda, Reale oferecer as bases para este artigo quando estabelece "(...) a consciência como possibilidade originária de síntese" (2002, p. 73), entendendo-se a síntese como: a "fusão de uma tese e de uma antítese numa noção ou numa proposição nova que retém o que elas têm de legítimo e as combina mediante a introdução de um ponto de vista superior" (FERREIRA, 1979, p. 1306).

$O$ direito enquanto realidade constituída a partir do mundo histórico-cultural tem na conduta humana a sua fonte constitutiva. Assim, há que se atentar para a necessária consistência das condutas sociais em geral e da jurídica em particular tendo em vista ser a conduta social a matéria prima da norma que institucionaliza esta mesma conduta (REALE, 1994, p. 76).

Lembra ainda Reale que o deve ser do homem está na raiz de seu ser histórico, muito embora as virtualidades de seu projetar-se temporal-axiológico não se exaure ao longo de sua existência (1994, p.79-80). Acrescenta o autor que um devir histórico nos moldes da teoria tridimensional vai implicar na constante e permanente atualização dos valores próprios dos momentos existenciais dos indivíduos e das coletividades (REALE, 1994, p. 82). O próprio homem reproduz a integração fáticoaxiológica neste mundo da cultura como numa extensão de si mesmo (REALE, 1994, p. 81).

Pelo exposto, torna-se possível inferir que o sentido que pode ser dado à história própria do direito reclama esta ser projetada a partir do próprio homem e do seu ser (REALE, 1994, p. 82). Para o Direito ainda é reservada a condição de guardião dos bens histórico-culturais adquiridos de modo a preservar o próprio homem e seu poder criador. 


\section{ตปthaคล์}

ISSN: 1984-6444 | http://dx.doi.org/10.5902/1984644436282

\section{Da pessoa ao cidadão}

Para ser cidadão não basta ter certidão de nascimento, votar, pagar tributos e obedecer às leis. Cidadania é compromisso consigo mesmo e com o passado, o presente e o futuro de um povo. É participação nas decisões e nas ações da sociedade. É, ao mesmo tempo, participação cultural, psíquica, ética, econômica, social e política.

Diferencia-se cidadão de pessoa em face da vinculação do primeiro com um Estado, "não havendo cidadão que não seja cidadão de um Estado" (DALLARI, 1984, p.3). Para Dallari (1984, p.3), “(...) em qualquer hipótese o cidadão é dependente do Estado, que estabelece as regras para aquisição da cidadania, diz quais são os direitos do cidadão e as condições para gozá-los".

A despeito de qualquer circunstância que vincule a pessoa a um Estado, possui ela características e necessidades que são próprias de sua condição humana. Neste sentido, nenhum Estado pode se olvidar de atender a tais características e necessidades, cabendo-Ihe promover os meios necessários e suficientes para tanto. Os direitos da pessoa humana são considerados mais importantes do que os direitos do Estado. Tal prerrogativa encontra-se estabelecida na Declaração Universal dos Direitos Humanos, aprovada pela Organização das Nações Unidas-ONU em 1948.

À luz do exposto, impõe-se a necessidade de defesa da pessoa humana, considerando-se, para tanto, que o fenômeno da exclusão atinge milhões de pessoas, quer seja, por sua deficiência física, quer seja, pelo analfabetismo, quer seja, pela falta de registro de nascimento e desemprego entre outros infortúnios sociais. Galgar da condição de pessoa à de cidadão, para muitos brasileiros, representa a conquista da própria sobrevivência.

\section{Educação e Justiça na construção da cidadania no Brasil}

Evidencia-se a preocupação com o papel da educação e da justiça como instrumentos de inclusão social e de construção da cidadania para o futuro sóciopolítico do Brasil. Importante reflexão sobre este binômio foi trazida por Paulo Afonso 


\section{Fusm Eulloahá}

ISSN: 1984-6444 | http://dx.doi.org/10.5902/1984644436282

Garrido de Paula, Procurador de Justiça do Estado de São Paulo, no âmbito do XVIII Congresso Brasileiro de Magistrados (PAULA, 2003, p.1-13).

Ao discorrer sobre o binômio mencionado, Paula procurou esclarecer sobre 0 termo educação que conceituou como sendo "um dos atributos da cidadania, sua própria essência e expressão", "direito e bem fundamental da vida" (2003, p.1). Acima de tudo, destacou ele o artigo 205 da CF que define a educação como: "(...) direito de todos e dever do Estado e da família, que será promovida e incentivada com a colaboração da sociedade, visando ao pleno desenvolvimento da pessoa, seu preparo para o exercício da cidadania e sua qualificação para o trabalho".

Afirma Paula que a Educação "representa para todos a capacitação para a felicidade, estado de êxito da pessoa humana" e a "porta da inclusão social" (2003, p.1). Tornando ao texto constitucional, a educação deve estar voltada para a adequada inserção do indivíduo em seu meio social. Cita-se a este respeito Lopes que afirma que: "entre os povos belicosos da antiguidade, o tipo perfeito era o valente soldado, tenaz à fadiga e dócil à disciplina (...)" (LOPES, 1927, p.19). E ainda, que entre todos os povos a direção dada ao ensino levava em conta as necessidades de seu meio (LOPES, 1927, p.18).

Trazendo-se tais considerações para os dias atuais, tem-se outro direcionamento dado à educação, ainda subordinado às necessidades do meio, direcionamento este representativo de uma mudança social que passa do interesse no domínio pelas armas e pela força física para uma prevalência no domínio pelo conhecimento, pela informação e pela experiência (SILVA ARAUJO, 2003, p. 44-45), reunindo, por sua própria constituição, condições mais favoráveis à inclusão da PcD.

Estes fundamentos, quando aplicados aos propósitos pretendidos de conscientização do direito, Ihe oferecem importante respaldo considerando-se que a consciência que se pretende seja adquirida pela $\operatorname{PcD}$ diz respeito a um direito que já Ihe foi concedido, que já é seu. Resta provado que a educação é o caminho viável para que se dê luz a essas pessoas do direito que possuem, além daquele estabelecido pela lei como hábil para o acesso à cidadania. Não se trata de ação assistencialista, mas da disponibilização dos instrumentos legalmente estabelecidos para o real engajamento social destas pessoas. 


\section{Fusm Eulloahá}

ISSN: 1984-6444 | http://dx.doi.org/10.5902/1984644436282

A educação é "direito de todos e dever do Estado" (BRASIL, CF. art. 205). Quando, por sua própria iniciativa, o indivíduo com deficiência buscar se educar, assumindo a consciência de sua cidadania estará, na verdade, cumprindo não só a lei como também um dever para consigo próprio e para com a sociedade (VON IHERING, 1997, p. 17) em prol da ordem social.

Tornando ao binômio, educação e justiça defendido por Paula, vem a justiça compor este quadro através da jurisdição inclusiva. Entende-se por jurisdição o "poder atribuído a uma autoridade para fazer cumprir determinada categoria de leis e punir quem as infrinja em determinada área" (FERREIRA, 1979, p. 808) e por jurisdição inclusiva, a "validação dos direitos sociais" (PAULA, 2003, p.4), único caminho para a superação da injustiça social. A lei “(...) não pode ser descartada enquanto embasamento estratégico para a inclusão" (PAULA, 2003, p.5). Note-se que o jurista quando atribui prevalência à legislação como fonte do direito permite vislumbrar um ponto de encontro com estudiosos como Bourdieu e Bobbio. Em relação ao primeiro, quando se refere ao "monopólio do direito de decidir o direito" (BOURDIEU, 2001, p.169) e, em relação ao segundo, quando atribui ao homem o poder de "transformar a sociedade através da renovação das leis que a regem" (BOBBIO, 1995, p.120 apud PAULA, 2003, p.5).

Cabe lembrar que o "(...) juiz é um dos construtores da cidadania na medida em que valida direitos sociais, garantindo a concretude dos direitos fundamentais" (PAULA, 2003, p.7). A inclusão social está atrelada ao uso e aplicação das normas estabelecidas na Constituição da República, em especial às representativas do modelo social por ela pretendido (PAULA, 2003, p.7).

Ressalta Paula a missão constitucional estabelecida no artigo $3^{\circ}$, inciso III, dentre os objetivos fundamentais do Estado brasileiro: “(...) erradicar a (...) marginalização e reduzir as desigualdades sociais (...)". Neste sentido, declara que é papel da justiça reforçar, sempre que não cumprido, o desígnio constitucional, de modo a garantir a "transposição da marginalidade para a cidadania" (2003, p.1).

Declara ainda que, uma vez que este "caminho já foi definido na Constituição da República”, não tem “(...) o Administrador, qualquer prerrogativa discricionária”, ou seja, qualquer opção de escolha (PAULA, 2003, p.13). E esclarece que o direito à 


\section{Autuaŗão}

ISSN: 1984-6444 | http://dx.doi.org/10.5902/1984644436282

educação é maior que o próprio indivíduo importando à própria sociedade como um todo (PAULA, 2003, p.13).

Ao final, pode-se inferir que a educação, assim como a justiça são instrumentos voltados para o bem comum. A educação objetiva o combate à marginalidade e à pobreza. E a justiça, objetiva a universalização desses direitos de inclusão social ou de cidadania para todos. O meio de efetivação do direito é pelo exercício da jurisdição que carece de ser inclusiva, mas para que se possa lançar mão dela, necessário se faz $\mathrm{o}$ assenhoreamento e a consciência deste direito. A lei, enquanto instrumento de exclusão que foi em período histórico anterior cede lugar para uma nova perspectiva de seu uso, agora como instrumento de inclusão, em especial, das PcD.

Ainda a Carta Magna de 1988, em seu art. $1^{\circ}$, inciso II, define o Brasil como um Estado Democrático de Direito que tem na cidadania um de seus fundamentos. É a Constituição brasileira o principal respaldo de que se necessita para o atingimento destes objetivos de igualdade, oferecendo o embasamento social, político e legal exigido para procurar levar o sentimento de pertencimento a esta parcela de brasileiros com deficiência.

A Lei de Diretrizes e Bases da Educação Nacional-LDB (Lei ํㅜ 9.394, de 20 de dezembro de 1996) estabelece em seu artigo $2^{\circ}$ a vinculação entre a educação e a cidadania. De acordo com este artigo, a educação nacional cumpre uma tríplice finalidade: "(...) o pleno desenvolvimento do educando, seu preparo para o exercício da cidadania e sua qualificação para o trabalho" (SILVEIRA, 2013, p.56).

As bases teóricas apresentadas demonstram, de modo incontestável, ser a educação o caminho para a formação da cidadania, e a justiça a detentora dos meios para tanto. Tais reflexões levam à conclusão de que se acrescido ao processo educacional padrão destes indivíduos elementos do Direito e seus fundamentos, as possibilidades buscadas de constituição de uma consciência cidadã teriam sim a chance de surgir e de se estabelecer. A confirmação desta verdade pode ser demonstrada pela aplicação de uma operação de caráter vetorial, onde o vetor Educação associado ao vetor Fundamentos do Direito e Leis traz como vetor soma ou resultante a consciência do direito cuja consequência é a conquista e o exercício da cidadania. Desta análise matemática pode-se concluir que a cada incremento do 


\section{ON Hsm

ISSN: 1984-6444 | http://dx.doi.org/10.5902/1984644436282

vetor Educação, associado ao respectivo incremento do vetor Fundamentos do Direito e Leis, torna-se possível obter maior consciência do direito e que esta consciência vá se formando e se estabelecendo paulatinamente à medida que o processo educativo específico se desenvolve dando chance ao surgimento de uma consciência cidadã.

É necessário que se note que a consciência do direito e a conquista da cidadania se encontram imbricadas, carecendo a última de conter a primeira para que de fato aconteça (Fig.4):

Figura 4: Configuração Vetorial do Processo

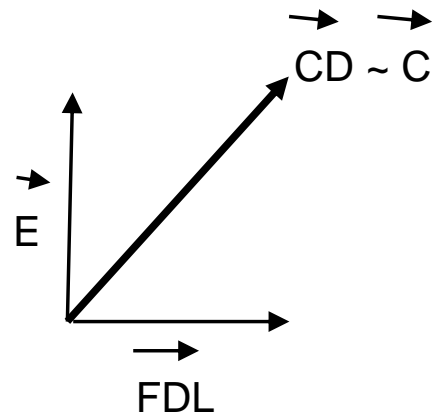

Legenda: $\vec{E}$-Educação; FDL-Fundamentos do Direito e Leis; $\overrightarrow{C D}$-Consciência do Direito; $\vec{C}$-Cidadania donde $\overrightarrow{\mathrm{CD}}=\overrightarrow{\mathrm{C}}=$ Vetor Soma ou Vetor Resultante

Fonte: Ilustração criada pela autora

\section{Objetivos}

O objetivo do presente artigo é o de apresentar, em linhas gerais, o projeto de curso elaborado. Desenvolvido na modalidade livre, buscou abarcar um elenco de conteúdos pedagógicos cuja assimilação pela PcD permitisse-Ihe a consciência de seus direitos em prol de sua inclusão social e exercício pleno da cidadania.

Fundamentou-se em trabalho de pesquisa de caráter histórico, sociológico, filosófico, econômico, jurídico e político. A posteriori selecionou conteúdos pertinentes e definiu seus parâmetros, quais sejam, objetivos, público alvo, carga horária, 


\section{Ej|lिa \\ 1SSN: $1984-6444$}

ISSN: 1984-6444 | http://dx.doi.org/10.5902/1984644436282

procedimentos metodológicos, de avaliação e bibliografia. Por último, promoveu a veiculação online do curso.

\section{Metodologia}

Visando o atendimento dos objetivos propostos foi formulada a seguinte pergunta: Quais conteúdos pedagógicos devem compor um programa de curso que contribua para o surgimento de uma consciência cidadã na PcD?

Para respondê-la foram realizados estudos bibliográficos, aplicados questionários do tipo aberto e realizadas entrevistas semi-estruturadas que culminaram com a formulação do programa de curso que incluiu conteúdos organizados em 10 (dez) aulas divididas em teóricas e práticas.

Por meio dos conteúdos teóricos buscou-se oferecer um breve enfoque sobre a História da PcD, além de uma visão sócio-filosófica de sua realidade. Nestes buscou-se facilitar a compreensão daqueles conteúdos considerados complexos, mas importantes para os propósitos de conscientização e inclusão.

Por sua vez, o texto das aulas de conteúdo prático contou com apresentação explicativa de um conjunto de leis eleitas como suficientes e bastantes para a efetiva proteção das $\operatorname{PcD}$ e buscou traduzir em linguagem simples, mas fidedigna, estes textos jurídicos. Instituiu-se um glossário com os termos que poderiam não ser de domínio dos cursistas e inseriu-se bibliografia específica para cada aula. Cada uma destas aulas contou com uma atividade de avaliação da aprendizagem.

Em relação a estes conteúdos teóricos, seus fundamentos respaldaram-se nos estudos desenvolvidos em: Michel Foucault, Miguel Reale, Pierre Bourdieu, Celso A. Pinheiro de Castro, Emílio Figueira, Otto Marques da Silva, Paulo Afonso Garrido de Paula e Dalmo de Abreu Dallari, dentre outros. E em relação aos conteúdos práticos foram adotados critérios de seleção de leis, privilegiando aquelas de espectro abrangente e ao mesmo tempo eficazes em relação aos propósitos definidos. Os critérios de ordenamento de sua apresentação atenderam, em primeiro lugar, à hierarquia jurídica, seguido da sequência temporal de promulgação destas. 


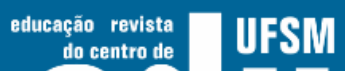 elithabá}

ISSN: 1984-6444 | http://dx.doi.org/10.5902/1984644436282

Deu-se preferência, com a exceção do Decreto 6.949/2009, à utilização das leis e não dos Decretos que as regulamentavam em função de que aquelas tratam diretamente do direito regulado e não da maneira como deve ser a lei aplicada, matéria mais afeta os decretos que, de regra, trazem os procedimentos de aplicação da lei. Desta forma a legislação selecionada foi organizada na ordem seguinte: Decreto $n^{\circ}$ 6.949/2009, por sua importância hierárquica (Emenda Constitucional); Lei 7.853/1989; Lei 10.098/2000 e Lei 13.146/2015, estas três últimas, em função de sua sequência temporal.

O Programa do Curso tomou a seguinte forma final (Fig.5).

Figura 5: Programa

(Espaço reservado para a logo das Instituições que chancelam o certificado do curso)

Curso

Programa

Modalidade: Livre $\quad \mathrm{C} / \mathrm{H}: 40 \mathrm{~h} / \mathrm{a}$

Público alvo: maiores de 18 anos com formação mínima de nível médio

Ementa

Fundamentos e Conceitos sobre Direito e Cidadania; Retrospectiva histórica da PcD; Análise da exclusão sob o ponto de vista cultural, social, político e econômico; Sistema Jurídico; Da pessoa ao cidadão: Diferença entre o ser e o deve ser; Educação e Justiça na Construção da Cidadania; Legislação pertinente.

\section{Objetivos}

Geral: Possibilitar a inclusão social da PcD pela via da consciência do Direito e do exercício pleno da cidadania.

Específico: Buscar o direito pelo conhecimento das leis e de seus fundamentos éticos, humanísticos e críticos.

\section{Conteúdo programático}

Aula 1 - Considerações sobre a origem e evolução do Direito. O cenário histórico da exclusão.

Aula 2 - Breves considerações sobre a história da PcD. O problema da PcD sob o ponto de vista cultural, social, político e econômico.

Aula 3 - Bem-estar social, ordem social e ordem jurídica. Direito e sistema jurídico. Norma versus lei. Da pessoa ao cidadão: Diferença entre o ser e o deve ser. Teoria Tridimensional de Miguel Reale.

Aula 4 - As PcD no contexto das políticas públicas.

Aula 5 - A educação e a justiça na construção da cidadania. A hierarquia das leis- A pirâmide de Kelsen. Aula 6 - Leis protetivas e PcD. Decreto 6.949/2009- Convenção Internacional dos Direitos da PcD.

Aula 7 - Leis 7.853/1989-Dispõe sobre o apoio às pessoas com deficiência, sua integração social, sobre a Coordenadoria Nacional para Integração da Pessoa Portadora de Deficiência- CORDE, institui a tutela jurisdicional de interesses coletivos ou difusos dessas pessoas, disciplina a atuação do Ministério Público, define crimes, e dá outras providências; Lei 10.098/2000- Lei da Acessibilidade.

Aula 8 - Lei 13.146/2015-Lei Brasileira de Inclusão- LBI, Arts. 01 a 41.

Aula 9 - Lei 13.146/2015-Lei Brasileira de Inclusão- LBI, Arts. 42 a 87. 


\section{N wrsw

ISSN: 1984-6444 | http://dx.doi.org/10.5902/1984644436282

\section{Continuação da Figura 5: Programa}

Aula 10 - Lei 13.146/2015-Lei Brasileira de Inclusão- LBI, Arts. 88 a 127.

\section{Procedimentos metodológicos}

Base teórica (18 h/a) - Conteúdos pedagógicos, conforme explicitado, de leitura obrigatória, distribuídos nas 5 (cinco) primeiras aulas, com intervalo de 15 (quinze) dias entre elas. Utilização do sistema online do tipo blog e correio eletrônico. Todo o material pedagógico é acompanhado das respectivas fontes bibliográficas, como também de breve glossário.

Base prática (22 h/a) - Conteúdos pedagógicos práticos, conforme explicitado, de leitura obrigatória, distribuídos nas 5 (cinco) últimas aulas, aplicados em conformidade com a sistemática adotada em relação aos conteúdos teóricos.

\section{Avaliação}

Disponibilizam-se junto aos conteúdos pedagógicos das aulas, atividades de verificação da aprendizagem, conforme calendário postado no blog. O descumprimento da atividade ou o atraso no seu envio é considerado para fins da avaliação final do aluno. A certificação recebe a chancela das instituições de apoio, além da assinatura da Coordenadora do Curso. Assim, a verificação é realizada de forma paulatina com base nas atividades acima referidas sendo que só é concedida certificação ao cursista que lograr cumprir todas as atividades do calendário de aulas com a média de aproveitamento mínimo Regular.

\section{Bibliografia básica}

BRASIL. Constituição da República Federativa do Brasil, promulgada em 05.10. 1988. In: http://www.planalto.gov.br/ccivil03/Constituicao/Constituicao.htm. Acesso em: 30.08.2018. BRASIL. Lei $n^{\circ}$-7.853, de 24 de outubro de 1989- Dispõe sobre o apoio às pessoas com deficiência, sua integração social, sobre a Coordenadoria Nacional para Integração da Pessoa Portadora deDeficiência- CORDE, institui a tutela jurisdicional de interesses coletivos ou difusos dessas pessoas, disciplina a atuação do Ministério Público, define crimes, e dá outras providểncias. In: http://www.planalto.gov.br/ccivil03/LEIS/L7853.htm. Acesso em: 04.11.2015.

BRASIL. Lei no 10.098, de 19 de dezembro de 2000- Estabelece normas gerais e critérios básicos para a promoção da acessibilidade das pessoas com deficiência ou com mobilidade reduzida, e dá outras providências. In: http://www.planalto.gov.br/ccivil03/LEIS/L10098.htm. Acesso em: 04.11.2015.

BRASIL. Decreto $n^{\circ}$ 6.949, de 25.08.2009- Promulga a Convenção Internacional sobre os Direitos das Pessoas com Deficiência e seu Protocolo Facultativo, assinados em Nova York, em 30 de março de 2007. In: http://www.planalto.gov.br/ccivil_03/_ato2007-2010/2009/decreto/d6949.htm. Acesso em: 04.11.2015.

BRASIL. Lei $n^{\circ}$ 13.146, de 6 de julho de 2015- Institui a Lei Brasileira de Inclusão da Pessoa com Deficiência. In: http://www.planalto.gov.br/ccivil03/Ato2015-2018/2015/Lei/L13146.htm Acesso em: 12.10.2015.

\section{Bibliografia complementar}

FIGUEIRA, E. Caminhando em Silêncio. São Paulo: Giz Editora. 2008.

SILVA, O. M. A Epopéia Ignorada: A Pessoa Deficiente na História do Mundo de Ontem e de Hoje. São Paulo: CEDAS, 1987.

VON IHERING, R. A luta pelo Direito. Trad. João de Vasconcelos. $16^{\mathrm{a}}$ ed. Rio de Janeiro: Forense. 1997.

Fonte: Extraído da pesquisa realizada pela autora 


\section{Wusm Eutlagha}

ISSN: 1984-6444 | http://dx.doi.org/10.5902/1984644436282

O Programa do Curso acima apresentado foi disponibilizado na forma online em plataforma virtual blog. O espaço educacional foi devidamente identificado, tendo como alvo a formação de multiplicadores, ou seja, pessoas aptas a difundir estes conhecimentos no futuro. A postagem de abertura ocorreu em 30.03.2017 (Fig.6).

Com o lançamento do blog, as atividades orientadoras de ensino passaram a ser desenvolvidas e iniciaram-se com a postagem sequencial das aulas, sempre acompanhadas das respectivas atividades de verificação da aprendizagem. Tais atividades tiveram como importante instrumento pedagógico de acompanhamento os contatos estabelecidos via e-mail que possibilitaram o esclarecimento de dúvidas e o reforço do processo educativo. Tal veículo de comunicação também possibilitou preservar a identidade, dados pessoais e acadêmicos.

Cada atividade de verificação da aprendizagem desenvolvida recebeu o respectivo Comentário Pedagógico o que contribuiu fortemente para a dinâmica do curso e para dirimir problemas na compreensão do material de estudo ocasionados por ruídos de comunicação. A postagem das aulas e o envio das atividades acadêmicas pelos cursistas seguiram calendário próprio.

Merece menção a postagem Destaques da Aula que desempenhou papel motivador, correspondendo a frases extraídas das atividades de verificação consideradas dignas do conhecimento público. As publicações foram devidamente autorizadas, bem como a divulgação das respectivas autorias. Após a conclusão do curso, as postagens Destaques de cada aula foram reunidas em postagem única que recebeu nova denominação: Melhores Momentos da Turma.

$\mathrm{Na}$ avaliação da última aula estabeleceu-se um caminho de mão e contramão. Junto à atividade da aula específica (aula 10) o cursista remete a avaliação que faz do curso, mediante instrumento oferecido no blog e recebe de volta, além do comentário específico sobre sua atividade de verificação da aula, os conceitos obtidos em cada uma delas e conceito final.

Foram implantados instrumentais de controle para o registro de dados pessoais e acadêmicos dos alunos como: Ficha de Inscrição; Ficha Individual de Avaliação da Aprendizagem; e Ficha de Controle de Desempenho Acadêmico-Turma_/_. O 


\section{T usm oltuaráo}

ISSN: 1984-6444 | http://dx.doi.org/10.5902/1984644436282

conceito atribuído a cada atividade obedeceu aos critérios de avaliação estabelecidos no Programa do Curso (Fig.5).

Ficou prevista a emissão de certificado a ser concedido ao cursista na dependência do cumprimento de todas as atividades do calendário com aproveitamento mínimo Regular, em conformidade com os critérios constantes do Programa de Curso. O certificado contou com a chancela das instituições apoiadoras, além da assinatura da autora, profissional com formação na área específica.

\section{Análise dos Resultados}

Os objetivos propostos foram encaminhados, ensejando um impacto positivo para o futuro que encontraram embasamento nos resultados extraídos de sua demanda formal e informal.

\section{Resultados da Demanda Formal do Curso}

A demanda formal oportunizou a formação de quatro turmas até o presente momento que contaram com um total de 38 (trinta e oito) cursistas matriculados, sendo que vinte concluíram e receberam certificação. A evasão correspondeu a 47\% (quarenta e sete).

$\mathrm{Na}$ avaliação média do desempenho acadêmico destas turmas já encerradas $40 \%$ (quarenta porcento) obteve conceito "Muito Bom" e 60\% (sessenta porcento) "Bom", o que se mostrou acima das expectativas.

Feita a análise do perfil dos cursistas (biodata) que englobou aqueles com frequência nas quatro turmas, pode-se levantar os dados constantes dos Quadros 1 e 2 abaixo.

Quadro 1: Estados de Origem

\begin{tabular}{|c|c|}
\hline Estado & Quantitativo \\
\hline $\mathrm{PR}$ & 2 \\
\hline $\mathrm{Pl}$ & 1 \\
\hline $\mathrm{RJ}$ & 17 \\
\hline Total & 20 \\
\hline
\end{tabular}

Fonte: Extraído dos registros cadastrais do curso 


\section{Nusm oltuaráo}

ISSN: 1984-6444 | http://dx.doi.org/10.5902/1984644436282

Quadro 2: Formação Acadêmica

\begin{tabular}{|c|c|}
\hline Formação acadêmica & Quantitativo \\
\hline Nível médio & 1 \\
\hline Graduação & 4 \\
\hline Pós lato sensu & 6 \\
\hline Mestrado & 9 \\
\hline Doutorado & 0 \\
\hline Total & 20 \\
\hline
\end{tabular}

Fonte: Extraído dos registros cadastrais do curso

O quantitativo de PcD no universo de cursistas certificados correspondeu a 4 (quatro), ou seja, 20\% (vinte porcento). O maior grupamento dentre os concluintes foi representado pelo contingente com formação acadêmica de nível superior, tais como: Ciências Biológicas, Direito, Fisioterapia, Fonoaudiologia, Gestão Ambiental, História, Letras, Odontologia, Pedagogia, Psicologia, Psicopedagogia e Serviço Social.

A avaliação realizada pelos cursistas concluintes apresentou-se bastante positiva e animadora, conforme tabulação e síntese apresentada adiante:

- Contribuição do curso para a formação pessoal e/ou profissional - 100\% (cem) respondeu afirmativamente à pergunta com as seguintes afirmações: “(...) possibilidade de conhecer e analisar a legislação (...) e como o Direito pode e deve contribuir para a efetivação dos direitos"; o curso "contribuiu e muito para a formação profissional" e para a aquisição de "conhecimentos sobre a PCD, sua história e avanços"; "Apresentou materiais que não conhecia e proporcionou-me aprofundar em detalhes de documentos que já tive acesso, mas de forma superficial".

- Pontos fortes e pontos a melhorar: Como pontos fortes a boa qualidade dos conteúdos foi ressaltada por $60 \%$ (sessenta porcento) dos respondentes. Outros comentários referiram-se ao benefício representado pela análise comentada das legislações: "o retorno dado após cada atividade"; a "flexibilidade" e a "compreensão acerca dos atrasos no envio das atividades"; as chamadas encaminhadas aos e-mails dos cursistas alertando-os sobre a postagem das aulas e ainda que "respondia sempre e-mails"; "os conteúdos foram de qualidade, nos transparecendo ser bem planejado, e assim, conseguindo alcançar os objetivos do curso"; "foi bem didático, começou com 


\section{T Ls" Eutlagha}

ISSN: 1984-6444 | http://dx.doi.org/10.5902/1984644436282

a história, bem resumido até chegar nos dias atuais"; e ainda, "Se houver continuação quero participar”. O quantitativo expressivo de $80 \%$ (oitenta porcento) dos respondentes declarou não haverem pontos a melhorar, muito embora algumas observações tenham sido colacionadas conforme a seguir: $O$ prazo de uma semana para o envio das atividades que segundo $80 \%$ (oitenta porcento) dos respondentes poderia ser ampliado; "A linguagem do direito, no início também me atrapalhou um pouco, mesmo com o glossário, agora já me habituei"; "a extensiva leitura, tendo em vista que, o meu tempo disponível é apenas no turno na noite, muitas vezes considerei a leitura maçante".

- Conteúdos do programa de curso, ou seja, se contribuíram para o atingimento dos propósitos a que se destina: A totalidade de respondentes declarou que sim, sendo que algumas considerações ainda foram oferecidas: "Possibilitou tomar conhecimento das leis e de seus fundamentos percebendo o Direito como instrumento capaz de efetivar tais leis"; "atendeu plenamente Direito e Cidadania"; "os conteúdos foram de qualidade, nos transparecendo ser bem planejado, e assim, conseguindo alcançar os objetivos do curso"; "O curso atingiu o objetivo pretendido".

- Sugestões: A totalidade dos respondentes declarou não ter sugestão para apresentar. Um respondente pediu "que seja repensada a dinâmica do curso online" em contraposição a um outro que declarou: "achei muito bom".

-Atendimento de expectativas: Novamente a totalidade dos respondentes declarou terem sido atendidas suas expectativas, acrescentando que: $O$ curso "possibilitou uma retomada histórica na trajetória da PCD (...) apresentou conceitos até então não analisados, ampliou minha visão sobre a aplicabilidade do Direito e do sistema jurídico e me fez ler e analisar a legislação vigente"; "nunca ter realizado um curso específico como esse"; "todos os temas das aulas e as verificações de aprendizagens foram de suma importância, tanto para a vida pessoal quanto formação profissional da educanda"; "apresentou materiais que não conhecia e proporcionou-me aprofundar em detalhes de documentos que já tive acesso, mas de forma superficial". 


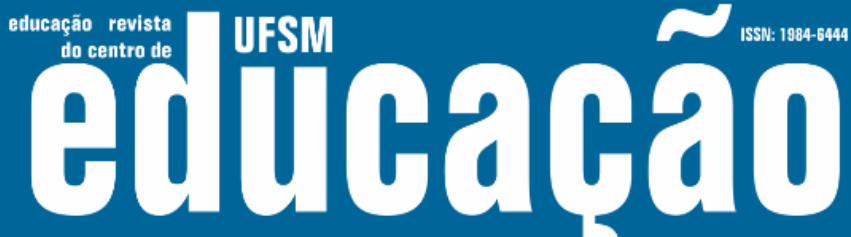

ISSN: 1984-6444 | http://dx.doi.org/10.5902/1984644436282

- Sugestões sobre o conteúdo e/ou sistemática de ensino-aprendizagem: O percentual de 40\% (quarenta porcento) não apresentou sugestão alguma, posição esta que ainda contou com o comentário: "Metodologia adotada excelente". Os demais respondentes, em declarações individuais, afirmaram: "Talvez fosse possível apresentar o conteúdo de forma mais dinâmica e trabalhar com documentários (não que não tenha sido apresentado), filmes, algo mais interativo. Isso é só sugestão porque o curso foi excelente"; E ainda, "Como conteúdo gostaria de ver contemplado os campos da Tecnologia Assistiva tão importante para a inclusão"; "talvez como sugestão indico que em algumas aulas, trabalhar também com alguma figura, esquema, para facilitar a aprendizagem. Apenas textos, podem cansar algumas pessoas".

\section{Resultados da Demanda Informal do Curso}

O blog do curso conta, atualmente, com 43 (quarenta e três) seguidores e alcança repercussão dentro e fora do Brasil, constituindo-se em importante demanda informal. Ao longo de aproximadamente 1 (um) ano e 6 (seis) meses de sua veiculação, foi computado pelo blogger, um total de 7.022 (sete mil e vinte e duas) visualizações que partiram de 3 (três) continentes (Americano, Asiático e Europeu) e abrangeram 9 (nove) países (Quadro 3).

Quadro 3: Visualizações de página público por país

\begin{tabular}{|c|c|}
\hline Entrada & Quantitativo \\
\hline Brasil & 6347 \\
\hline Estados Unidos & 547 \\
\hline Rússia & 93 \\
\hline Índia & 14 \\
\hline França & 07 \\
\hline Alemanha & 05 \\
\hline Peru & 04 \\
\hline Espanha & 03 \\
\hline Reino Unido & 02 \\
\hline Total & 7022 \\
\hline
\end{tabular}

Fonte: Extraído da página específica do blog (Acesso em: 09.10.2018) 


\section{ตปthaคล์}

ISSN: 1984-6444 | http://dx.doi.org/10.5902/1984644436282

As visualizações acima apresentadas parecem representar uma diferente forma de atingimento dos objetivos propostos. $O$ fato fortalece a iniciativa à medida que mais pessoas tomam conhecimento dos conteúdos que nele estão sendo postados. As visualizações realizadas a partir dos EUA têm se mantido constantes, só sendo inferiores àquelas do território nacional.

\section{Conclusão}

O curso pode e deve sempre ser melhorado e difundido, não só com o aprimoramento de sua dinâmica como também de seu conteúdo. Os ajustes recomendados pelas avaliações dos cursistas são passíveis de serem introduzidos em prol do atingimento dos objetivos de contribuir para a consciência do direito como via de acesso à cidadania.

Aspira-se que tenha uma influência positiva na vida das pessoas e que, no futuro, possa conduzir-se na esteira da transversalidade e da interdisciplinaridade, como também no sentido e na direção dos princípios que sustentam os ideais da nova cidadania.

\section{Referências}

BOURDIEU, Pierre. Poder, Derecho y Clases Sociales. Bilbao: Desclée de Brouwer. 2001.

BRASIL. Constituição da República Federativa do Brasil, promulgada em 05 de outubro de $1988 . \quad$ Disponível em: http://www.planalto.gov.br/ccivil03/Constituicao/Constituicao.htm. Acesso em: 30.08.2018.

BRASIL. Lei no 9.394, de 20 de dezembro de 1996. Estabelece as diretrizes e bases da educação nacional. Lei de Diretrizes e Bases da Educação- LDB. Disponível em: http://www.planalto.gov.br/ccivil_03/Leis/L9394.htm. Acesso em: 04.11.2015.

CASTRO, Celso Antônio Pinheiro de. Sociologia do Direito. $8^{a}$ ed. São Paulo: Atlas. 1996.

DALLARI, Dalmo de Abreu. Direitos Humanos e Cidadania. São Paulo: Moderna, 1984. 


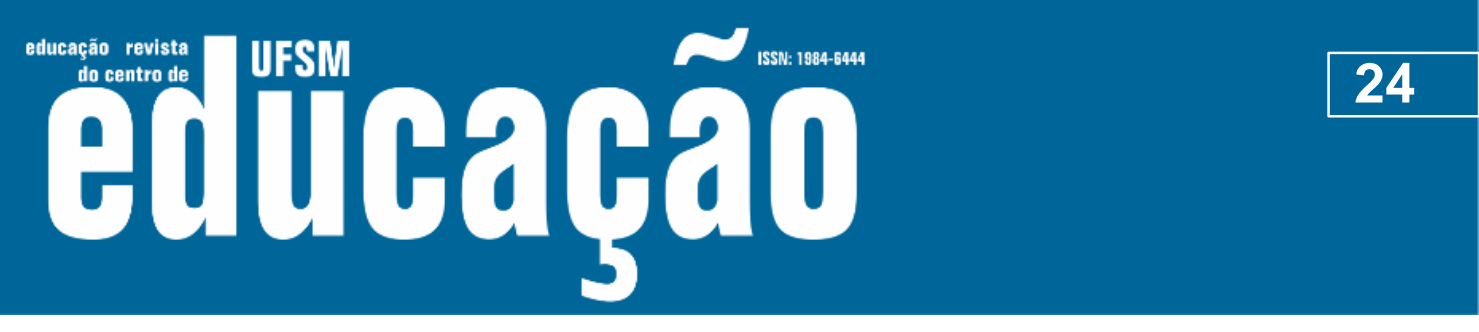

ISSN: 1984-6444 | http://dx.doi.org/10.5902/1984644436282

FERREIRA, Aurélio Buarque de Holanda. Novo Dicionário da Língua Portuguesa. São Paulo: Cia. Brasileira de impressão e propaganda. 1979.

GARCIA, Vinicius Gaspar; MAIA, Alexandre Gori. A inclusão das pessoas com deficiência e/ou limitação funcional no mercado de trabalho brasileiro em 2000 e 2010: Panorama e mudanças em uma década. In: XVIII ENCONTRO NACIONAL DE ESTUDOS POPULACIONAIS DA ASSOCIAÇÃO BRASILEIRA DE ESTUDOS POPULACIONAIS. 18., 2012, São Paulo. Anais eletrônicos. São Paulo: ABEP. 2012. Disponível em: http://www.abep.nepo.unicamp.br/xviii/anais/files/ST15\%5B89\%5DABEP2012.pdf. Acesso em: 20 abr. 2017.

IHERING, Rudolf Von. A luta pelo Direito. 16 ed. Rio de Janeiro: Forense. 1997.

I.SOCIAL. Soluções em Inclusão Social. Profissionais de Recursos Humanos: Expectativas e Percepções sobre a Inclusão de Pessoas com Deficiência no Mercado de Trabalho 2016. Série Histórica: 2014/2015/2016. Disponível em: http://isocial.com.br/isocialdownload.php. Acesso em: 14 dez.2017.

LOPES, Antonia Ribeiro de Castro. O Ensino Deve Obedecer ao Meio. In: LOPES, Antonia Ribeiro de Castro. Synopse de Pedagogia e Methodologia Didactica. Campos- E. do Rio: TYP A' PENNA DE BRONZE, 1927. p.18-21.

PAULA, Paulo Afonso Garrido. Justiça e Educação como Instrumento de Inclusão Social. In: CONGRESSO BRASILEIRO DE MAGISTRADOS, 18, 2003, Salvador. Associação de Magistrados Brasileiros- AMB. Disponível em: http://www.amb.com.br/portal/docs/noticias/noticia107.pdf. Acesso em: 28 jan.2017.

PORTAL BRASIL. Cresce número de Pessoas com Deficiência no Mercado de Trabalho Formal. Disponível em: http://www.brasil.gov.br/economia-eemprego/2016/09/cresce-numero-e-pessoas-com-deficiencia-no-mercado-detrabalho-formal. Acesso em: 12 fev. 2017.

REALE, Miguel. Teoria Tridimensional do Direito. 5ª Ed. São Paulo: Saraiva, 1994. REALE, Miguel. Lições Preliminares de Direito. 27ª Ed. São Paulo: Saraiva, 2002.

SILVA ARAUJO, Angela Maria da. A globalização. In: SILVA ARAUJO, Angela Maria da. Seleção de pessoas para um novo paradigma com apoio fuzzy. Rio de Janeiro: Faculdades IBMEC, 2003. p.44-45.

SILVEIRA, Renê José Trentin. Ensino de Filosofia e Cidadania: Uma Abordagem a partir de Gramsci. Revista Brasileira de Estudos Pedagógicos, Brasília. Vol. 94, n. 236, 2013. Disponível em: http://www.scielo.br/pdf/rbeped/v94n236/04.pdf. Acesso em: 05 nov.2015.

UNRIC. Centro Regional de Informação das Nações Unidas. Alguns Factos e Números sobre as Pessoas com Deficiência. Disponível em: http://www.unric.org/pt/pessoas-com-deficiencia/5459. Acesso em: 09.fev.2017. 


\section{$=0$

ISSN: 1984-6444 | http://dx.doi.org/10.5902/1984644436282

\section{Correspondência}

Tatiana de Araujo Mendonça - Universidade Federal Fluminense- Rua Miguel de Frias, 9, Icaraí, CEP 24220-900, Niterói, Rio de Janeiro, Brasil.

\section{(c) (i) (9)}

This work is licensed under a Creative Commons Attribution-NonCommercial 4.0 International (CC BY-NC 4.0) 